\title{
1 Wing-pattern-specific effects of experience on mating behavior in Heliconius
}

\section{2 melpomene butterflies}

3 Peyton A. Rather*, Abigail E. Herzog*, David A. Ernst, Erica L. Westerman

4 Department of Biological Sciences, University of Arkansas, Fayetteville, AR 72701

$5 \quad$ *equal contributors

\section{Abstract}

9 Many animals have the ability to learn, and some taxa have shown learned mate preference. This

10 learning may be important for speciation in some species. The butterfly Heliconius melpomene is

11 a model system for several areas of research, including hybridization, mate selection, and

12 speciation, partially due to its widespread diversity of wing patterns. It remains unclear whether

13 these butterflies can learn to prefer certain mates and if social experience shapes realized mating

14 preferences. Here we test whether previous experience with a female influences male mate

15 preference for two different $H$. melpomene subspecies, $H$. m. malleti and $H$. m. rosina. We

16 conducted no-choice behavioral assays to determine if latency to court and whether males

17 courted (vs no courtship) differed between naïve males and males with previous exposure to a

18 young, sexually mature, virgin female. To test whether assortative courtship preference is

19 learned in H. melpomene, males were either paired with a female who shared their phenotype or

20 one who did not. Naïve H. m. malletti males courted assortatively, while naïve H.m. rosina males

21 did not. Experienced H. m. malleti males reduced their courting relative to naïve males,

22 suggesting that social experience with a sexually mature female that does not result in copulation

23 may be perceived as a negative experience. In contrast, experienced H. m. rosina males exhibited 
bioRxiv preprint doi: https://doi.org/10.1101/2020.07.15.205435; this version posted July 17, 2020. The copyright holder for this preprint (which

was not certified by peer review) is the author/funder, who has granted bioRxiv a license to display the preprint in perpetuity. It is made available under aCC-BY-NC-ND 4.0 International license.

24 similar courting rates to naïve $H$. m. rosina males. Our results suggest that social experience can

25 influence male mating behavior in H. melpomene and that behavioral plasticity may differ across

26 populations in this species.

27

28 Keywords

29 behavioral plasticity, mate choice, Lepidoptera, assortative mating, social learning, male choice

30

31

32

33

34

35

36

37

38

39

40

41

42

43

44

45

46 


\section{Introduction}

49 Many of the behaviors and decisions that an animal makes are affected by its observations and

50 capacity to learn. Learning can be defined as a set of processes that allows an animal to acquire,

51 store, and use information gathered from the environment (Galef and Laland, 2005). Learning in

52 animals is often complex and is likely the result of the social dynamics and settings of a species

53 (Coussi-Korbel and Fragaszy, 1995). There is a substantial amount of evidence that animals have

54 the ability to socially learn (Dukas, 1998). Some of the many behaviors that might be the result

55 of social learning include food choices, predator avoidance, and mate preferences. For example,

56 many species of fish have been observed to learn how to find food, how to recognize predators,

57 and how to assess mate quality (Brown and Laland, 2003). This breadth of learning ability,

58 however, is not limited to vertebrates (Dukas, 2008; Verzijden et al., 2012).

60 It is now understood that learning affects many essential activities of invertebrates, including

61 predator avoidance and social interactions (Dukas, 2008, 2010). Particularly, many insects and

62 spiders have shown the ability to learn mate preference. Studies on the wolf spider Schizocosa

63 uetzi have shown that female social experience in their penultimate juvenile period can affect

64 their mate choices as adults (Hebets, 2003). Female Teleogryllus oceanicus crickets modify

65 their mate preferences after hearing attractive male songs (Bailey and Zuk, 2009), and female

66 Bicyclus anynana butterflies learn preferences for enhanced male ornaments (Westerman et al.,

67 2012). Male B. anynana also learn preferences for wing pattern elements in females (Westerman

68 et al., 2014). Furthermore, work with Drosophila melanogaster fruit flies have shown that

69 learning to be selective leads to a higher lifetime mating success than males who court 
70 indiscriminately (Dukas et al., 2006). Therefore, when it comes to mate preference and sexual

71 behavior in insects it is often beneficial to learn.

72

73 Learning can potentially increase rates of assortative mating, which can lead to speciation

74 through processes such as when young animals imprint on parents (Dukas, 2013). One such

75 example of this is how cross-fostering experiments in two subspecies of zebra finch

76 demonstrated that assortative mating is due to imprinting. Birds in this study paired with mates

77 that resembled their foster parents instead of their own phenotype (Irwin and Price, 1999). It has

78 also been shown that mate preference can be learned in mature animals, such as male guppies

79 and Syrian hamsters. These animals have demonstrated learning to discriminate against

80 heterospecific mates after courtship interactions (Verzijden et al., 2012). This type of learning

81 would help maintain speciation. With these studies in mind, we might expect that Heliconius

82 butterflies, or other animals with high levels of speciation, might learn to court assortatively.

84 Heliconius butterflies have a long lifespan compared to other species of butterflies, which allows

85 them to potentially mate multiple times (Gilbert, 1972). Therefore, the ability to learn in

86 response to mating experiences could be advantageous. Studies have shown that male mate

87 preferences evolve early in the speciation process in Heliconius within both intraspecific hybrid

88 mating zones and conspecific polymorphic populations (Merrill et al., 2011a). These male mate

89 preferences are based on wing color pattern cues, which are under natural selection to correspond

90 to local mimetic environments (Gray and McKinnon, 2007; Kronforst et al., 2006). Heliconius is

91 well known for its diversity in color patterns, and divergence in these color morphs is associated

92 with speciation and adaptive radiation (Heliconius-Genome-Consortium* et al., 2012). 
94 Here we take advantage of the social butterfly species Heliconius melpomene, whose widespread

95 diversity of color patterns makes it an ideal model for studies on speciation and mating patterns

96 (Jiggins et al., 2004). In this species, mimetic color patterns play a key role in species

97 recognition, and mate preferences based on these patterns evolve alongside changes in wing

98 pattern (Jiggins et al., 2004). Previous studies show that mimetic coloration in this species is

99 important in choosing mates, and that these butterflies show assortative mating when choosing

100 between their own and a different, closely related species (Heliconius cydno) (Jiggins et al.,

101 2001). Furthermore, males often do discriminate between conspecific females with different

102 wing patterns, and do not copy the mate preferences of conspecific males who have different

103 wing patterns (Jiggins et al., 2004). However, it remains unclear whether individual $H$.

104 melpomene males use past social experience with sexually receptive (or non-receptive) females

105 to inform current mating decisions. The ability to learn mate preferences for intraspecies

106 variation in wing pattern may be important for the initiation of assortative mating, reproductive

107 isolation, and the speciation process.

108

109 Here we test whether experience impacts future male mate preference and courting behavior in

110 two races of $H$. melpomene using three distinct $H$. melpomene color morph phenotypes (Figure

111 1). We had three alternative hypotheses: 1) If males learn, then we predicted that experienced

112 males would be more likely to court and have a shorter latency to court relative to naïve males.

113 This type of learning is seen in B. anynana, where males exposed to dorsal hindwing spot

114 number variation learn preferences for this trait (Westerman et al., 2014). 2) If however male

115 exposure to a female is somehow a negative experience, then we predicted that experienced 
116 males would court less often than naïve males. This type of learning is seen in Drosophila males.

117 Studies have shown that naïve male Drosophila court virgin females persistently, while males

118 previously exposed to an unreceptive female will then court virgin females much less vigorously

119 (Siegel and Hall, 1979). 3) If males are not able to learn, then courting was predicted to occur at 120 random in both experienced and naïve males. An example of this is seen in the butterfly Papilio

121 polytes, where a series of behavioral assays studying male preference for mimetic and non-

122 mimetic females showed that there was no difference in initial and lifetime male preference,

123 regardless of number of failed courtship attempts (Westerman et al., 2018).

\section{Materials and Methods}

\section{Study species and husbandry}

128 Heliconius melpomene is a widespread neotropical butterfly found in Central and South America

129 (Brower, 1994; Sheppard et al., 1985). The species is well known for its high diversity in color

130 patterns, which play an important role in speciation (Jiggins et al., 2004). These color patterns,

131 though diverse, are largely sexually monomorphic, with females and males of each morph

132 having predominantly identical wing patterns. H. melpomene is often used as a model organism

133 to study Müllerian mimicry and is co-mimetic with the species Heliconius erato (Jiggins et al.,

134 2004). The many color patterns of $H$. melpomene have arisen through convergent evolution and

135 selection for mimicry. The diversity of these patterns have allowed for the species to be used as

136 models for studies on speciation and mating patterns (Jiggins, 2017). Here we take advantage of

137 this species with different morphs that sometimes cohabitate in nature. 
H. melpomene butterflies were either reared in a greenhouse at the University of Arkansas, or were obtained as pupae from Costa Rica Entomological Supply (Alajuela Apo. 2132-4050 Costa

141 Rica.). Butterflies reared from the greenhouse colony came from a continuously breeding colony

142 kept in two, phenotypic-specific, walk-in cages $(143.51 \times 110.25$ x $219.71 \mathrm{~cm})$. Caterpillars from

143 the colony were given Passiflora plants ad libitum, and prior to pupation, plants containing

144 caterpillars were removed from the breeding cages and moved to a separate $60.96 \times 60.96 \times$

$145 \quad 142.24 \mathrm{~cm}$ cage until butterfly emergence from pupa. Pupae obtained from Costa Rica

146 Entomological Supply were reared on native Passiflora host plants in natural lighting as

147 caterpillars prior to pupation and shipping. When at the University of Arkansas, they were hung

148 in a $34.29 \times 34.29 \times 60.96 \mathrm{~cm}$ cage until emergence, and then maintained as adults in the

149 Department of Biological Sciences Greenhouse at the University of Arkansas.

151 Butterflies were maintained at approximately $27^{\circ} \mathrm{C}$, an average relative humidity of $71.5-85 \%$,

152 and a 13:11 light:dark cycle. The greenhouse was lit by Sun Blaze T5 high output 120-volt

153 fluorescent light fixtures (containing UV wavelengths), in addition to natural sunlight, and the

154 presence of UV light in the greenhouse was confirmed using an Ocean Optics Jaz spectrometer.

155 After emergence, each butterfly was sexed, marked with a unique number on their hind wing

156 (which does not harm the butterflies, see (Gall, 1984) for details), and then moved to $60.96 \mathrm{x}$

$15760.96 \times 142.24 \mathrm{~cm}$ cages with food where they were kept until use in a behavioral watch. Males

158 were placed into sex- and phenotype-specific cages, so they were isolated from both females and

159 other wing patterns prior to behavioral assays. Females were placed into sex- but not phenotype-

160 specific cages, so they were familiar with the wing patterns of males they were paired with in

161 later behavioral assays. Each cage contained no more than 15 butterflies at any time and was 
162 visually isolated so that butterflies could not see individuals of the opposite sex (or phenotype in

163 the case of males). Butterflies were fed BIRDS choice butterfly nectar (Birds Choice, Chilton,

164 WI, USA), which is composed of glucose, fructose, calcium salt, halide salt, and amino acids. In

165 addition, cages also contained Passiflora and Lantana plants for supplemental nectar and pollen.

166 All behavioral watches were conducted in 60.96 x 60.96 x 142.24 cm BioQuip (Rancho

167 Dominguez, CA, USA) observation cages, visually isolated from all other cages, between August 1682017 and November 2019.

170 Observational Experiment Time of Day Selection

171 To determine the time of day when the butterflies were the most active, we observed butterflies

172 in colony cages for three consecutive days, between 6:00 am and 8:00 pm. Point counts were

173 conducted every thirty minutes, where behaviors (flight, walk, flutter, abdomen lift, bask [defined

174 by resting with wings held in open position], rest [defined by resting with wings held in closed

175 position], antennae wiggle, court, and copulate) were recorded for each cage, followed by two

176 ten-minute focal watches of one male and one female butterfly selected at random. Based on

177 observations, we determined that butterflies were most active between the hours of 10:00 am to $178 \quad 2: 00 \mathrm{pm}$.

Behavioral Watches

181 All behavioral watches took place between 10:00 am and 2:00 pm, the time of peak $H$.

182 melpomene activity in our greenhouse. Each watch consisted of a male aged ten or twelve days

183 old, and a female between three and five days old. Watches were set up based on four separate

184 treatments, $\mathrm{N}=15$ per treatment per male phenotype. In this study, two male phenotypes were 
used ( H. m. malleti and H. m. rosina) and three female phenotypes were used (H. m. malleti, H. m. rosina, and H. m. plessini) (Figure 1). To test whether males courted females with matching

187 wing patterns faster than they courted conspecific females with dissimilar wing patterns, we

188 tested latency to courtship and presence of courtship of naïve, 12-day-old H.m. malleti and H.m. rosina males matched with either females of their own phenotype or females of different (naïve) male was exposed to a female (with either a similar or dissimilar phenotype) until he either courted the female or 90 minutes passed without courtship. Afterward, the female was

193 removed, and the male was returned to the all-male, phenotype-specific cage. On day 12, these

194 males (i.e., experienced males) were exposed to a second female of the phenotype to which they

195 had been previously exposed. The behavior of these males was then compared to that of naïve, 196 12-day-old males exposed to similar or dissimilar wing patterned females.

198 On the morning of a watch, a male was placed into an observation cage approximately two to

199 three hours before the watch to acclimate to the new setting, and a female was added right before

200 the start of a watch. Once a trial began, butterflies were observed for 90 minutes or until

201 courtship took place. In the case that courtship did occur, time to court was recorded, and

202 butterflies were not allowed to copulate. Behaviors were recorded to determine if any had an

203 effect on mate preference. The number of incidents of each type of behavior (flight, walk, flutter,

204 abdomen lift, bask (wings open), rest (wings closed), antenna wiggle, sitting near, and court)

205 were recorded. Spectator Go BIOBSERVE (Fort Lee, NJ, U.S.A.) running on an Apple iPad was

206 used to record time to court and all behaviors of the male and female during the testing period. 


\section{Statistical Analyses}

209 All statistical analyses were performed in JMP v. 14 (SAS Institute, Cary, NC, U.S.A.). We

210 assessed whether latency to court was influenced by male experience or female wing pattern

211 (similar or different from the male's) using a GLM with male experience and female wing

212 pattern as factors, as well as an interaction term. To assess if there was an effect of experience or

213 female wing pattern on likelihood to court we ran a nominal logistic regression model using male

214 experience and female wing pattern as factors, as well as an interaction term. Since we used two

215 different morphs for our "different female" treatments (H.m. plesseni and H.m. rosina for H. m.

216 malleti males; and H. m. plesseni and H. m. malleti for H. m. rosina males), we also tested

217 whether there was an effect of female phenotype on male likelihood to court in our four different

218 phenotype treatments using nominal logistic regression models. To test whether female behavior

219 during a male's first experience with a female had an effect on the observed courtship behavior

220 in later interactions with females, we analyzed all behavioral data collected on day 10 watches

221 ( $=51$ watches with behavioral data) and examined whether any of these behaviors were

222 predictive of male courting on day 12. To do this we ran a principal components analysis on all

223 the female behaviors and then ran logistic regression models on the first three principal

224 components.

Ethical Note

227 All H. melpomene butterflies were kept under laboratory conditions as defined by U.S.

228 Department of Agriculture, Animal and Plant Health Inspection Service permit P526P-17-00343.

229 Before being used in behavioral watches all butterflies were maintained in cages in a climate-

230 controlled setting in conditions similar to those of their native habitat, and cages were inspected 
231 daily for ample food and appropriate conditions. All males and females used in a behavioral

232 watch were either euthanized by freezing for use in future analyses or added to colony breeding

233 cages where they were maintained in cages with ample food until natural death.

\section{Results}

Experienced $H$. m. malleti males were less likely to court females than naïve $H$. m. malleti males,

239 and were more likely to court H. m. malleti females than either H. m. rosina or H. m. plessini

240 females (nominal logistic regression model, whole model $\chi^{2}=14.935, \mathrm{p}=0.0019, \mathrm{AICc}=75.900$,

$241 \mathrm{~N}=60$; male experience $\chi^{2}=8.85, \mathrm{p}=0.009$; female phenotype (same or different) $\chi^{2}=6.85$,

$242 \mathrm{p}=0.009$; interaction $\chi^{2}=0.07, \mathrm{p}=0.794$ ) (Figure 2A). However neither experience nor female

243 wing pattern influenced $H$. m. rosina male's likelihood to court (nominal logistic regression

244 model, whole model $\chi^{2}=0.472, \mathrm{p}=0.925, \mathrm{AICc}=92.852 ; \mathrm{N}=63$, male experience $\chi^{2}=0.313$,

$245 \mathrm{p}=0.576$; female phenotype (same or different) $\chi^{2}=0.126, \mathrm{p}=0.722$; interaction $\chi^{2}=0.029$,

$246 \mathrm{p}=0.864$ ) (Figure 2B). The effect of prior exposure to a female on likelihood of H.m. malleti to

247 court two days later was independent of whether the male courted during the initial exposure

248 period (nominal logistic regression model, whole model $\chi^{2}=3.099, p=0.377, \mathrm{~N}=30$; courted

249 initially $\chi^{2}=0.182, \mathrm{p}=0.670$; female phenotype $\chi^{2}=2.325, \mathrm{p}=0.127$; interaction $\chi^{2}=0.181$,

$250 \mathrm{p}=0.671)$. Male courtship response to females with different wing patterns was independent of

251 the female wing pattern the male saw (H. m. rosina or H. m. plesseni for H. m. malleti males:

252 nominal logistic regression model, whole model $\chi^{2}=3.513, \mathrm{p}=0.319, \mathrm{~N}=30$; female phenotype

$253 \chi^{2}=0.683, \mathrm{p}=0.409 ;$ male experience $\chi^{2}=2.305, \mathrm{p}=0.129 ;$ interaction $\chi^{2}=0.391, \mathrm{p}=0.531 ; H . \mathrm{m}$. 
254 malleti or H. m. plesseni for H. m. rosina males: nominal logistic regression model, whole model

$255 \chi^{2}=0.188, \mathrm{p}=0.979, \mathrm{~N}=32$; female phenotype $\chi^{2}=0.002, \mathrm{p}=0.966$; male experience $\chi^{2}=0.387$,

$256 \mathrm{p}=0.844$; interaction $\left.\chi^{2}=0.112, \mathrm{p}=0.738\right)$.

257

$258 \quad$ No effect of experience or female wing pattern on latency to court

259 For those males that did court during the 90 minute observation period, there was no effect of

260 experience or female wing pattern on male latency to court, for either H.m. malleti or H.m.

261 rosina ( GLM, H.m.malleti, whole model $\mathrm{F}$ ratio=0.391, $\mathrm{p}=0.761, \mathrm{~N}=23$; male experience $\mathrm{F}$

262 ratio $=0.375, \mathrm{p}=0.548$; female phenotype $\mathrm{F}$ ratio $=0.599, \mathrm{p}=0.449$; interaction $\mathrm{F}$ ratio $=0.038$,

$263 \mathrm{p}=0.848 ;$ H.m. rosina, whole model $\mathrm{F}$ ratio $=1.663, \mathrm{p}=0.205, \mathrm{~N}=25$; male experience $\mathrm{F}$

264 ratio $=0.200, \mathrm{p}=0.659$; female phenotype $\mathrm{F}$ ratio $=3.22, \mathrm{p}=0.087$; interaction $\mathrm{F}$ ratio $=1.452$,

$265 \mathrm{p}=0.242)$.

266

267

Female Behavior Had No Effect on Future Likelihood to Court

268 We found no effect of female behavior during first exposure on male courtship rates during

269 second exposure (Table 1 and 2).

270

271 Discussion

272

273 Our results show that male $H$. melpomene butterflies change their mating behavior in response to

274 a social experience. This change in behavior is lineage specific, with H. m. malleti males, but not

275 H. m. rosina males, exhibiting a reduction in likelihood to court after a social experience where

276 they interact, but do not get to copulate, with a conspecific female. This effect was independent 
277 of the female's wing pattern, though it did co-occur with a lineage-specific preference for

278 assortative mating. H. m. malleti males courted H. m. malleti females more often than H. m.

279 rosina and $H$. m. plesseni females in no-choice assays, while H. m. rosina males courted all

280 female $H$. melpomene wing patterns equally often. Male likelihood to court was not significantly

281 influenced by female behavior, and when males did court, experienced males did not court faster

282 than naïve males.

Heliconius butterflies have many of the characteristics often found in species where past

285 experience informs future social behavior; thus, our finding that $H$. melpomene males modify

286 their mating behavior in response to experience, while novel, may not be unexpected. $H$.

287 melpomene butterflies are relatively long-lived (up to 6 months in nature) (Gilbert, 1972), highly

288 social (they roost in groups at night) (Mallet and Gilbert, 1995), and learn food sources and color

289 cues (Toure et al., 2020). They have large brains (Montgomery et al., 2016) and are both

290 physically larger, and longer lived than the butterfly Bicyclus anynana, which also uses past

291 experience to inform current mating behavior (Dion et al., 2020; Westerman et al., 2012;

292 Westerman et al., 2014). However, the negative effect of the pre-mating social exposure, and the

293 wing-pattern-specific response to this pre-mating social exposure, were unexpected.

295 We initially hypothesized that early exposure to a female would prime the males to court faster

296 and more often upon second exposure to females. This was based on previous findings in $B$.

297 anynana, where naïve males do not exhibit a mate preference, but males with previous social

298 experience do (Westerman et al., 2014). However, we found instead that early exposure to a

299 female was a negative experience for $H$. m. malleti males, as they tended not to court on the 
repeat trial when exposed to a female of the same wing pattern and age as they had previously

301 seen. One possible cause for this negative response could be that males who do court on day 10

302 are pulled from the watch upon courtship and are not allowed to copulate. This type of negative

303 learning occurs in Drosophila melanogaster males, where previously unsuccessful males are

304 reluctant to court females who smell similarly to females who previously rejected them (Griffith

305 and Ejima, 2009; Siegel and Hall, 1979). Heliconius butterflies do have species-specific

306 olfactory signals which are used in mating decisions (González-Rojas et al., 2020; Mérot et al.,

307 2015), and olfactory signals have been shown to influence visual learning in $B$. anynana

308 butterflies (Westerman and Monteiro, 2013). It would be interesting to see if olfactory cues play

309 a similar role in Heliconius.

311 Although males did not learn to prefer certain phenotypes, avoidance learning from a negative

312 experience could be beneficial to these males. D. melanogaster males have demonstrated

313 learning to reduce courting females of the species Drosophila simulans, as these females

314 typically reject mating attempts by male D. melanogaster (Dukas, 2004). Heterospecific

315 courting can be costly for males because they could be wasting time and energy courting females

316 that are likely to reject them (Dukas, 2009). This suggests that learning to avoid unreceptive

317 females, or learning mate preference in general, may be beneficial relative to indiscriminately

318 courting females. Negative learning in H. m. malleti may therefore lead to higher lifetime mating

319 success, particularly if females who reject them once are likely to reject them again, and re-

320 encounter rates are high due to nighttime social roosting. 
322 It is worth noting that a characteristic of the social experience we used, the removal of a male as

323 soon as he initiated courtship, resembles a component of the experimental design historically

324 used in Heliconius butterfly mate choice trials. In many studies, males are allowed to approach a

325 female and initiate courtship, and then they are physically removed from the female before given

326 an opportunity to copulate (Chamberlain et al., 2009; Kronforst et al., 2006; Merrill et al., 2019;

327 Merrill et al., 2011b). These males are then tested repeatedly, and past experience is often not

328 accounted for when male preference is assessed, assuming that past experience does not inform

329 present courting decisions. This assumption is partially based on a previous study showing that

330 exposure to conspecific females with different wing patterns does not induce a preference for

331 those wing patterns (Jiggins et al., 2004). However, this earlier study did not test for a negative

332 effect of exposure on male preference or courtship behavior. Our results support the previous

333 finding that prior exposure does not induce a positive preference, but suggest it instead may be a

334 negative experience, at least for $H$. m. malleti. This wing-pattern specific response to experience

335 should be seen as a cautionary tale for future comparative research with Heliconius butterflies, as

336 repeated trials may be experienced differently by different lineages, which could confound

337 interpretation of results. It also highlights the importance of checking for both positive and

338 negative valence when testing the presence of learning.

340 The presence of both a lineage-specific response to prior experience and a lineage-specific

341 presence of assortative courtship suggest that $H$. m. malleti and $H$. m. rosina may experience

342 different mating-related selective pressures. Maintaining the capacity to learn can be

343 energetically costly, and is often associated with fitness trade-offs, such as reduced fecundity

344 (Kotrschal et al., 2013; Snell-Rood et al., 2011), reduced lifespan (Burger et al., 2008; Kotrschal 
et al., 2019), or extended development time (Kolss and Kawecki, 2008). Though conspecifics, $H$.

m. malleti and H. m. rosina rarely co-occur in nature (Brower, 1996). The stronger innate

347 preference and response to prior social experience exhibited by $H$. m. malleti suggest that $H . m$.

348 malleti butterflies may, on average, co-occur with a more diverse Heliconius butterfly

349 community than $H$. m. rosina butterflies, as is suggested by previously published range maps

350 (Brower, 1996; Sheppard et al., 1985). This could lead to the maintenance of male assortative

351 courtship and response to prior social experience in H. m. malleti, as limiting courtship efforts to

352 those most likely to be successful would be energetically adaptive in an environment with many

353 unreceptive females (Dukas et al., 2006). Assortative courtship and response to prior social

354 experience may not be as strong in H. m. rosina as a result of either differences in generational

355 exposure to polymorphic conspecifics, or differences in female receptivity. If most $H$.

356 melpomene females are receptive to $H$. m. rosina males, independent of female wing pattern,

357 there would be little pressure for males to maintain an assortative preference among conspecific

358 wing patterns, or to maintain the ability to use past social experience to inform current courting

359 behavior.

$361 H$. m. malleti's response to prior experience could be associated with its assortative preference or

362 a high social learning capacity. If $H$. m. malleti males have a stronger innate assortative

363 preference than $H$. m. rosina males, it is possible that the initial exposure to a female creates a

364 stronger negative memory for $H . m$. malleti males than for H. m. rosina males. Aversive signals

365 are easier than appetitive signals for D. melanogaster to learn, and this is hypothesized to be due

366 to the type of response to the initial cue (Schwaerzel et al., 2003). Alternatively, H. m. malleti

367 might have a higher learning capacity (social or otherwise) than H. m. rosina. Heliconius cydno 
368 and Heliconius melpomene have different sized brain neuropils associated with sensory

369 processing (Montgomery et al., 2020); it would be interesting to see if similar neuropil variation,

370 and associated variation in learning, occurs in $H . m$. malleti and H. m. rosina. Future research

371 should examine the neural responses of $H . m$. malleti and H. m. rosina males to an early social

372 experience, as well as their relative flower color and nectaring location learning abilities and

373 neural anatomy, to determine the mechanisms underlying their observed difference in response

374 to prior social experience.

375

\section{Conclusion}

378 Here we show that male $H$. melpomene butterflies use past social experience to inform current

379 mating behavior. This response is lineage (wing pattern) specific, and coincides with lineage-

380 specific differences in male assortative preference. Our findings strongly suggest that there are

381 lineage-specific selective forces acting on cognitive function in Heliconius butterflies. Future

382 research should explore the effect of cognition on speciation in this speciose group.

\section{Acknowledgements}

385 We would like to thank Alexis Okoro for assistance with data processing, and Sushant Potdar,

386 Grace Hirzel, Matt Murphy, Dylan Meyer, and Tim Sullivan for assistance with butterfly

387 husbandry. This research was funded by the University of Arkansas. 


\section{Data Accessibility Statement}

392

393

Analyses reported in this article can be reproduced using the data provided by Rather et al., (XXX).

\section{References}

Bailey NW, Zuk M, 2009. Field crickets change mating preferences using remembered social information. Biological Letters 5:449-451. doi: 10.1098/rsbl.2009.0112.

Brower AVZ, 1994. Rapid morphological radiation and convergence among races of the butterfly Heliconius erato inferred from patterns of mitochondrial DNA evolution. Proceedings of the National Academy of Sciences of the United States of America 91:6491-6495.

Brower AVZ, 1996. Parallel race formation and the evolution of mimicry in Heliconius butterflies: A phylogenetic hypothesis from mitochondrial DNA sequences Evolution 50:195-221.

Brown C, Laland KN, 2003. Social learning in fishes: a review Fish and Fisheries 4:280-288. doi: 10.1046/j.1467-2979.2003.00122.x.

Burger JMS, Munjong K, Pont J, Kawecki TJ, 2008. Learning ability and longevity: A symmetrical evolutionary trade-off in Drosophila. Evolution 62:1294-1304. doi: 10.1111/j.1558-5646.2008.00376.x.

Chamberlain NL, Hill RI, Kapan DD, Gilbert LE, Kronforst MR, 2009. Polymorphic butterfly reveals the missing link in ecological speciation. Science 326:847-850.

Coussi-Korbel S, Fragaszy DM, 1995. On the relation between social dynamics and social learning. Animal Behaviour 50:1441-1453.

Dion E, Pui LX, Weber K, Monteiro A, 2020. Early-exposure to new sex pheromone blends alters mate preference in female butterflies and in their offspring. Nature Communications 11. doi: 10.1038/s41467-019-13801-2.

Dukas R, 1998. Cognitive Ecology: The evolutionary ecology of information processing and decision making. The University of Chicago Press.

Dukas R, 2004. Male fruit flies learn to avoid interspecific courtship. Behavioral Ecology 15:695-698. doi: 10.1093/beheco/arh068.

Dukas R, 2008. Evolutionary Biology of Insect Learning. Annual Review of Entomology 53:145-160. doi: 10.1146/annurev.ento.53.103106.093343.

Dukas R, 2009. Dynamics of learning in the context of courtship in Drosophila persimiis and $D$. pseudoobscura. Animal Behaviour 77:253-259.

Dukas R, 2010. Social learning in insects. Encyclopedia of Animal Behavior 17:176-179.

Dukas R, 2013. Effects of learning on evolution: robustness, innovation and speciation. Animal Behaviour 85:1023-1030. doi: 10.1016/j.anbehav.2012.030.

Dukas R, Clark CW, Abbott K, 2006. Courtship strategies of male insects: when is learning advantageous? Animal Behaviour 72:1395-1404. 
Galef BG, Laland KN, 2005. Social learning in animals: Emperical studies and theoretical models. BioScience 55:489-499.

Gall LF, 1984. The effects of capturing and marking on subesquent activity in Boloria acrocnema (Lepidoptera: Nymphalidae), with a comparison of different numerical models that estimate population size. Biological Conservation 28:139-154.

Gilbert LE, 1972. Pollen feeding and reproductive biology of Heliconius butterflies. Proceedings of the National Academy of Sciences of the United States of America 69:1403-1407.

González-Rojas MF, Darragh K, Robles J, Linares M, Schulz S, McMillan WO, Jiggins C, Pardo-Diaz C, Salazar C, 2020. Chemical signals act as the main reproductive barrier between sister and mimetic Heliconius butterflies. Proceedings of the Royal Society of London B 287:20200587. doi: 10.1098/rspb.2020.0587.

Gray SM, McKinnon JS, 2007. Linking color polymorphism maintenance and speciation. Trends in Ecology \& Evolution 22:71-79. doi: 10.1016/j.tree.10.005.

Griffith LC, Ejima A, 2009. Courtship learning in Drosophila melanogaster: Diverse plasticity of a reproductive behavior. Learning \& Memory.

Hebets EA, 2003. Subadult experience influences adult mate choice in an arthropod: Exposed female wolf spiders prefer males of a familiar phenotype. Proceedings of the National Academy of Sciences of the United States of America 100:13390-13395.

Heliconius-Genome-Consortium*, *Dasmahaptra KK, Walters JR, Briscoe AD, Davey JW, Whibley A, Nadeau NJ, Zimin AV, Hughes DST, Ferguson LC, Martin SH, Salazar C, Lewis JJ, Aldler S, Ahn S, Baker DA, BAxter SW, Chamberlain NL, Chuahan R, Counterman BA, Dalmay T, Gilbert LE, Gordon K, Heckel DG, Hines HM, Hoff KJ, Holland PWH, Jacquin-Joly E, Jiggins FM, Jones RT, Kapan DD, Kersey P, Lamas G, Lawson D, Mapleson D, Maroja LS, Martin A, Moxon S, Plamer WJ, Papa R, Papanicolaou A, Pauchet Y, Ray DA, Rosser N, Salzberg SL, Supple MA, Surridge A, Tenger-Trolander A, Vogel H, Wilkinson PA, Wilson D, Yorke JA, Yuan F, Balmuth AL, Eland C, Gharbi K, Thomson M, Gibbs RA, Han Y, Jayaseelan JC, Kovar C, Mathew T, Muzny DM, Ongeri F, Pu L, Qu J, Thornton RL, Worley KC, Wu Y, Linares M, Blaxter ML, ffrench-Constant RH, Joron M, Kronforst MR, Mullen SP, Reed RD, Scherer SE, Richards S, Mallet J, McMillan WO, Jiggins CD, 2012. Butterfly genome reveals promiscuous exchange of mimicry adaptations among species. Nature 487:94-98. doi: 10.1038/nature11041.

Irwin DE, Price T, 1999. Sexual imprinting, learning and speciation. Heredity 82:347-354.

Jiggins C, 2017. The ecology and evolution of Heliconius butterflies. Oxford: Oxford University Press

Jiggins CD, Estrada C, Rodrigues A, 2004. Mimicry and the evolution of premating isolation in Heliconius melpomene Linnaeus. Journal of Evolutionary Biology 17:680-691. doi: 10.1111/j.1420-9101.2004.00675.x.

Jiggins CD, Naisbit RE, Coe RL, Mallet J, 2001. Reproductive isolation caused by colour pattern mimicry Nature 411:302-305.

Kolss M, Kawecki TJ, 2008. Reduced learning ability as a consequence of evolutionary adaptation to nutritional stress in Drosophila melanogaster. Ecological Entomology 33:583-588.

Kotrschal A, Corral-Lopez A, Kolm N, 2019. Large brains, short life: selection on brain size impacts intrinsic lifespan. Biology Letters 15:20190137. doi: 10.1098/rsbl.20190137. 
Kotrschal A, Rogell B, Bundsen A, Svensson B, Zajikschek S, Brännström I, Immler S, Maklakov AA, Kolm N, 2013. Artificial selection on relative brain size in the guppy reveals costs and benefits of evolving a larger brain Current Biology 23:168-171. doi: 10.1016/j.cub.2012.058.

Kronforst MR, Young LG, Kapan DD, McNeely C, O'Neill RJ, Gilbert LE, 2006. Linkage of butterfly mate preference and wing color preference cue at the genomic location of wingless. Proceedings of the National Academy of Sciences of the United States of America 103:6575-6580.

Mallet J, Gilbert LE, 1995. Why are there so many mimicry rings? Correlations between habitat, behaviour and mimicry in Heliconius butterflies. Biological Journal of the Linnean Society 55:159-180.

Mérot C, Frérot B, Leppik E, Joron M, 2015. Beyond magic traits: Multimodal mating cues in Heliconius butterflies. Evolution 69:2891-2904. doi: 10.1111/evo.12789.

Merrill RM, Gompert Z, Dembeck LM, Kronforst MR, McMillan WO, Jiggins CD, 2011a. Mate preference across the speciation continuum in a clade of mimetic butterflies. Evolution 65:1489-1500. doi: 10.1111/j.1558-5646.2010.01216.x.

Merrill RM, Rastas P, Martin SH, Melo MC, Barker S, Davey JW, McMillan WO, Jiggins CD, 2019. Genetic dissection of assortative mating behavior. PLoS Biology 17:e2005902. doi: 10.1371/journal.pbio.2005902.

Merrill RM, Van Schooten B, Scott JA, Jiggins CD, 2011b. Pervasive genetic associations between traits causing reproductive isolation in Heliconius butterflies. Proceedings of the Royal Society of London B 278:511-518. doi: 10.1098/rspb.2010.1493.

Montgomery SH, Merrill RM, Ott SR, 2016. Brain composition in Heliconius butterflies, posteclosion growth and experience-dependent neuropil plasticity. The Journal of Comparative Neurology 524:1747-1769. doi: 10.1002/cne.23993.

Montgomery SH, Rossi M, McMillan WO, Merrill RM, 2020. Neural divergence and hyrid disruption between ecologically isolated Heliconius butterflies. bioRxiv. doi: 10.1101/2020.07.01.182337.

Schwaerzel M, Monastirioti M, Scholz H, Friggi-Grelin F, Birman S, Heisenberg M, 2003. Dopamine and octopamine differentiate between aversive and appetitive olfactory memories in Drosophila. Journal of Neuroscience 23:10495-10502.

Sheppard PM, Turner JRG, Brown KS, Benson WW, Singer MC, 1985. Genetics and the evolution of Muellerian mimicry in Heliconius butterflies. Philosophical Transactions of the Royal Society B 308:433-610.

Siegel RW, Hall JC, 1979. Conditioned responses in courtship behavior of normal and mutant Drosophila. Proceedings of the National Academy of Sciences of the United States of America 76:565-578.

Snell-Rood EC, Davidowitz G, Papaj DR, 2011. Reproductive tradeoffs of learning in a butterfly. Behavioral Ecology 22:291-302. doi: 10.1093/beheco/arq169.

Toure MW, Young FJ, McMillan WO, Montgomery SH, 2020. Heliconiini butterflies can learn time-dependent reward associations. bioRxiv. doi: 10.1101/2020.06.06.135459.

Verzijden MN, ten Cate C, Servedio MR, Kozak GM, Boughman JW, Svensson EI, 2012. The impact of learning on sexual selection. Trends in Ecology and Evolution 27:511-519. doi: 10.1016/j.tree.2012.05.007. 
521 Westerman E, Hodgins-Davis A, Dinwiddie A, Monteiro A, 2012. Biased learning affects mate choice in a butterfly. Proceedings of the National Academy of Sciences of the United States of America 109:10948-10953. doi: 10.1073/pnas.1118378109.

Westerman E, Monteiro A, 2013. Odour influences whether females learn to prefer or to avoid wing patterns of male butterflies. Animal Behaviour 86:1139-1145. doi: 10.1016/j.anbehav.2013.09.002.

Westerman EL, Chirathivat N, Schyling E, Monteiro A, 2014. Mate preference for a phenotypically plastic trait is learned, and may facilitate preference-phenotype matching. Evolution 68:1661-1670.

Westerman EL, Letchinger R, Tenger-Trolander A, Massardo D, Palmer D, Kronforst MR, 2018. Does male preference play a role in maintainng female limited polymorphism in a Batesian mimetic butterfly? Behavioural Processes 150:47-58. doi: 10.1016/j.beproc.2018.02.014.

Figure 1. Heliconius melpomene phenotypes. A) H. m. malletti, B) H. m. rosina, and C) H. m.

544 plesseni.

545

546 Figure 2. Lineage-specific effect of experience on male courtship. A) H. m. malleti reduce

547 courtship after exposure to, but not copulation with, a female $\left(\mathrm{N}=60\right.$, male experience $\chi^{2}=8.85$,

$548 \mathrm{p}=0.009$; female phenotype (same or different) $\chi^{2}=6.85, \mathrm{p}=0.009$; interaction $\chi^{2}=0.07, \mathrm{p}=0.794$ ).

549 B) $H . m$. rosina do not $\left(\mathrm{N}=63\right.$, male experience $\chi^{2}=0.313, \mathrm{p}=0.576$; female phenotype (same or

550 different) $\chi^{2}=0.126, \mathrm{p}=0.722$; interaction $\left.\chi^{2}=0.029, \mathrm{p}=0.864\right)$. 
554 Tables and Table Legends

555

556

Table 1. Loadings for principle components from PCA for female behavior during the training

557 period for day 10 males.

558

559

560

561

562

563

564

565

566

567

568

569

570

571

572

573

574

575

576

577

578

579

580

581

582

583

\begin{tabular}{|l|l|l|l|}
\hline & PC 1 & PC 2 & PC 3 \\
\hline Flutter Count $(C t)$ & 0.513 & 0.091 & 0.046 \\
\hline Fly Ct & 0.432 & -0.047 & -0.134 \\
\hline Walk Ct & 0.441 & -0.171 & -0.010 \\
\hline Lift Abdomen Ct & 0.061 & 0.216 & 0.817 \\
\hline Bask Ct & 0.292 & 0.023 & 0.023 \\
\hline Court Ct & -0.032 & 0.548 & -0.516 \\
\hline Ant Wiggle Ct & 0.235 & -0.416 & -0.160 \\
\hline Resting Ct & 0.19372 & 0.035 & 0.096 \\
\hline Sitting Near Ct & 0.414 & 0.662 & 0.013 \\
\hline \% Variance Explained & 34.712 & 14.446 & 11.563 \\
\hline \% Total Variance Explained & 34.712 & 49.158 & 60.721 \\
\hline
\end{tabular}


584 Table 2. Female behavior during early exposure did not influence male likelihood of courting in

585 later female encounters. Test statistics and p-values from logistic regression models using

586 composite behavioral variables PC1, PC2, PC3. N=51.

587

588

589

590

591

592

593

594

595

596

597

598

599

600

601

602

603

604

605

606

607

608

609

\begin{tabular}{|l|l|l|l|}
\hline & PC 1 & PC 2 & PC 3 \\
\hline $\boldsymbol{\chi}^{\mathbf{2}}$ & 0.046 & 0.013 & 1.460 \\
\hline P-value & 0.830 & 0.907 & 0.226 \\
\hline
\end{tabular}

.


Figures

612

613

614

\section{Figure 1.}

A)

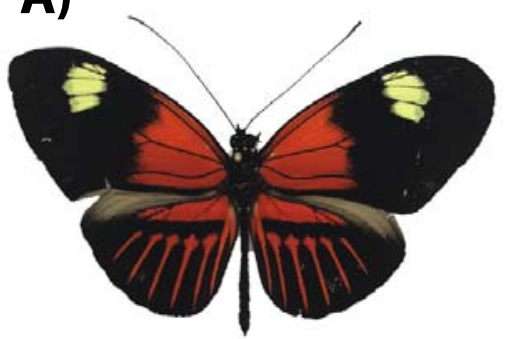

B)

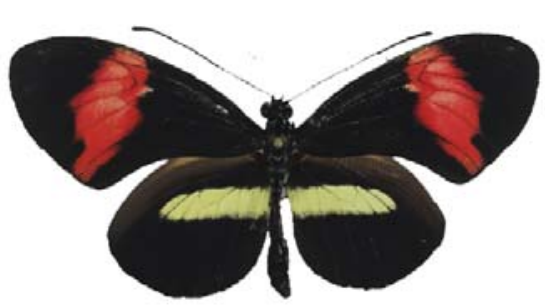

C)

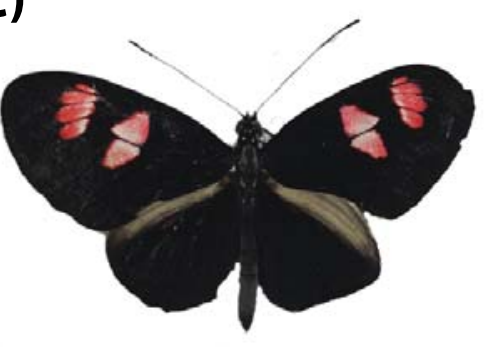

\section{5}


bioRxiv preprint doi: https://doi.org/10.1101/2020.07.15.205435; this version posted July 17, 2020. The copyright holder for this preprint (which was not certified by peer review) is the author/funder, who has granted bioRxiv a license to display the preprint in perpetuity. It is made available under aCC-BY-NC-ND 4.0 International license.

Figure 2.

646

647

A)

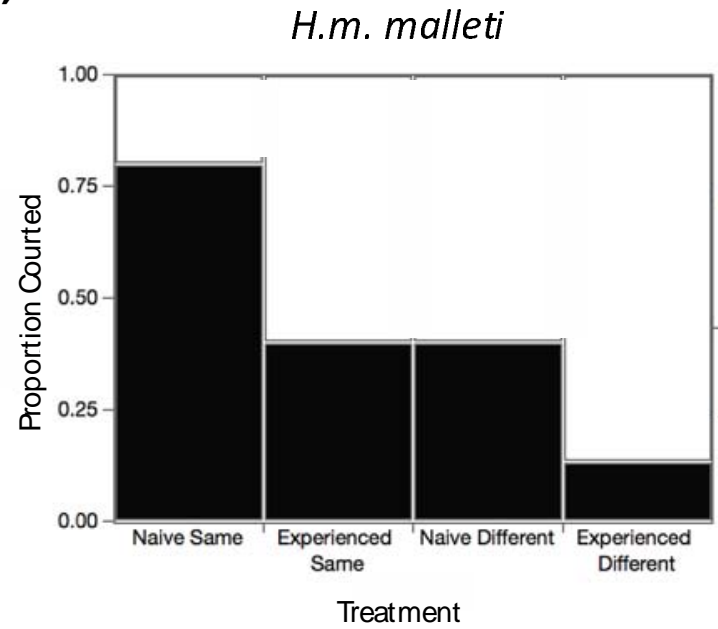

B)

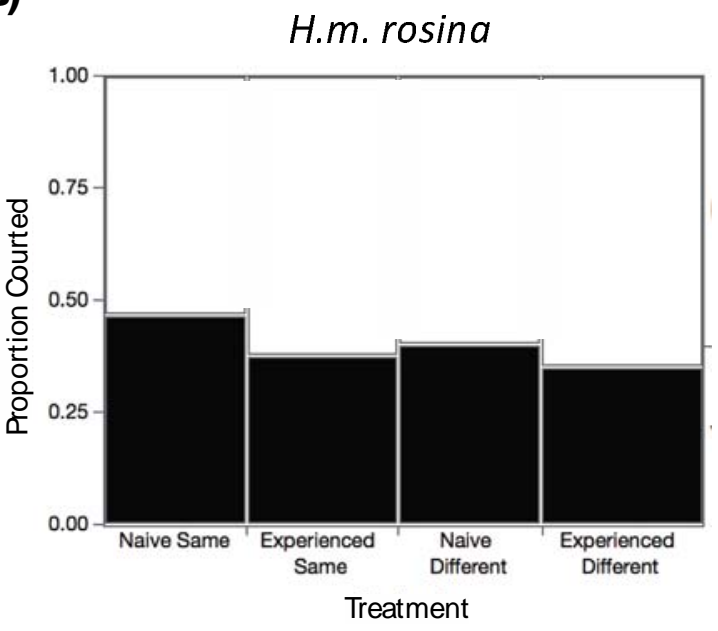

